Check for updates

Cite this: RSC Adv., 2017, 7, 31980

Received 1st April 2017

Accepted 12th June 2017

DOI: $10.1039 / c 7 r a 03780 e$

rsc.li/rsc-advances

\title{
Injectable and thermoresponsive pericardial matrix derived conductive scaffold for cardiac tissue engineering $\dagger$
}

\author{
Kaveh Roshanbinfar, ${ }^{\text {ab }}$ Jöns Hilborn, ${ }^{\mathrm{b}}$ Oommen P. Varghese (iD ${ }^{\mathrm{b}}$ \\ and Oommen P. Oommen (iD *bc
}

Scaffolds derived from decellularized cardiac tissue offer an enormous advantage for cardiac applications as they recapitulate biophysical and cardiac specific cues. However, poor electrical conductivity and mechanical properties severely compromise the therapeutic potential of these matrices. Dispersion of multiwall carbon nanotubes (MWCTs) in these scaffolds could improve their mechanical and electrical properties. However, the inherent hydrophobicity and poor dispersibility of these materials under aqueous conditions limit their outcome. We have developed a modified MWCNT functionalized with carbodihydrazide $(\mathrm{CDH})$ residues that significantly improved their dispersibility and suppressed cytotoxicity in HL-1 cardiomyocytes. We found that the doping of $\mathrm{CDH}$ functionalized MWCNT (CDHMWCNT) as low as $0.5 \mathrm{wt} \%$ to the pericardial matrix hydrogel (PMNT) induced the necessary electrical conductivity and significantly improved the mechanical properties of the hydrogel. Cardiomyocytes cultured on a PMNT scaffold triggered proliferation and significantly increased the expression of cardiacspecific gap junction protein, namely connexin 43. Such a phenomenon was not observed when cardiomyocytes were cultured on the pericardial matrix derived gels without MWCNT or on gelatinfibronectin coated 2D cultures. The PMNT gels displayed excellent biophysical characteristics resulting in the clustering of cardiomyocytes with synchronous contraction, which is crucial for the successful integration to the host tissue.

\section{Introduction}

The limited regenerative capacity of the heart, especially after myocardial infarction (MI) results in progressive cardiac failure and subsequent death. The only available treatment currently is the highly invasive total heart transplantation, although there is a lack of sufficient donors and long waiting lists for the recipients. ${ }^{1}$ Tissue engineering offers an exciting alternative treatment for MI that could regenerate and rejuvenate the injured cardiac tissue. One experimental approach for treating MI is cellular cardiomyoplasty; however, limited cell survival and immune rejection are major problems. On the other hand, cardiac patches containing autologous stem cells in a hydrogel scaffold are an alternative approach; ${ }^{2}$ nonetheless, poor

\footnotetext{
${ }^{a}$ Experimental Renal and Cardiovascular Research, Department of Nephropathology, Institute of Pathology, Friedrich-Alexander-Universitaet Erlangen-Nuernberg (FAU), Erlangen, Germany

${ }^{b}$ Department of Chemistry, Angstrom Laboratory, Uppsala University, SE 75121 Uppsala, Sweden

'Bioengineering and Nanomedicine Lab, Biomaterials and Tissue Engineering Group, BioMediTech Institute and Faculty of Biomedical Sciences and Engineering, Tampere University of Technology, Tampere, 33720, Finland. E-mail: oommen.oommen@tut.fi $\dagger$ Electronic supplementary information (ESI) available: Supplementary videos and immunostaining images. See DOI: 10.1039/c7ra03780e
}

integration of the grafts with the surrounding tissue poses insurmountable challenges in these strategies. ${ }^{2}$ Cell-free, scaffold-based therapies are an attractive and potentially costeffective method for treating MI hearts. The key to the success of such approaches relies heavily on the scaffold design, which should (a) promote native cell migration, retention, and survival, (b) assist in the graft integration, (c) provide immune protection and (d) promote angiogenesis and neovascularization. Furthermore, an ideal scaffold design for cardiac tissue engineering should present the fundamental cardiac specific cues, and provide suitable mechanical properties, and comparable electrical conductivity. Several natural hydrogels derived from the extracellular matrix (ECM) such as decellularized urinary bladder, ${ }^{3}$ pericardium, ${ }^{4}$ and myocardial matrix $^{5,6}$ hydrogels have been examined for cardiac regeneration. Among them, matrix derived from decellularized pericardium is unique as it is not a vital organ and has the feasibility to be used as an autologous tissue while contains the necessary ECM components of the native pericardium. The decellularized cardiac scaffolds were found to improve the cardiac function after MI by decreasing wall stress and inhibiting scar tissue formation. ${ }^{6,7}$ However, the electrical conductivity is crucial for efficient cardiac regeneration and function, ${ }^{8}$ as the adult cardiomyocytes are not autonomously electroactive and need to be 
stimulated by the electrical current conducted through Purkinje fibers. The poor electrical conductivity of the decellularized matrices poses a major drawback. Thus, there is a need to design an electroconductive scaffold with appropriate mechanical and biological properties that would be able to evoke contractility comparable to the native cardiac tissue and support the proliferation of cardiomyocytes. The electrical conductivity in hydrogel scaffolds for tissue engineering applications could be induced by incorporating different conductive polymers such as polyanilines (PANI), polypyrroles (PPys), polythiophenes etc., exhibiting different mechanical and electrical properties. ${ }^{9}$ Cardiomyocytes cultured on PPy containing electrospun membrane demonstrated enhanced adhesion, proliferation and expression of cardiac specific markers. ${ }^{10}$ Although they have shown to promote cellular adhesion, proliferation and differentiations, there are other reports that indicate poor biocompatibility of the materials containing these polymers. ${ }^{\mathbf{1 1 , 1 2}}$ Carbon nanotubes (CNT) are ideal materials for fabricating hydrogels as they possess limited cytotoxicity, enhance mechanical properties and are responsive for cardiac cells. ${ }^{13}$ CNTs grafted on glass surfaces or in gelatin hydrogels successfully promoted electrical conductivity and triggered proliferation of cardiomyocytes. ${ }^{\mathbf{1 4}}$ Here we hypothesized that an electroconductive hydrogel based on the injectable decellularized pericardial tissue with tailored mechanical properties would support cardiomyocyte proliferation and function. In order to test the hypothesis, chemically functionalized multiwall carbon nanotubes (CDH-MWCNT) have been used to improve mechanical properties as well as the electrical conductivity of the pericardial derived hydrogels (PM); then, HL-1 cardiomyocytes cultured on these gels and their proliferation, function and beating properties were studied.

\section{Materials and methods}

\section{Multiwall carbon nanotubes functionalization}

Carboxylic acid functionalized multiwall carbon nanotubes (8 wt\%) were bought from Sigma (Cat number 755125) and hydrazide functionalized using a standard $\mathrm{N}$-(3-diethylaminopropyl)- $N^{\prime}$-ethylcarbodiimide (EDC) coupling as described before ${ }^{15}$ with a slight modification. Briefly, $100 \mathrm{mg}$ COOH-MWCNT were dispersed in $50 \mathrm{~mL}$ distilled water by sonication for 30 minutes. Thereafter, $0.44 \mathrm{mmol}$ carbodihydrazide (CDH) (Sigma C11006) and $0.11 \mathrm{mmol}$ hydroxybenzotriazole (HOBt) (Sigma 54802) were dissolved in $50 \mathrm{~mL}$ distilled water separately and added to $\mathrm{COOH}-\mathrm{MWCNT}$ containing solution and the $\mathrm{pH}$ was adjusted to 4.7. To this solution, $0.088 \mathrm{mmol}$ of EDC (Sigma 39391), was added and stirred overnight at room temperature. Thereafter, the sample was dialyzed through $3.5 \mathrm{kDa}$ dialysis membranes (Spectra Pro-3, MWCO $3.5 \mathrm{kDa})$ against dilute $\mathrm{HCl}(\mathrm{pH}=3)$ (Fisher scientific 1330572) and 0.1 M NaCl (Fisher scientific 1416237) for one day and deionized water for two days. After dialysis, samples were collected and lyophilized (SCANLAF Coolsafe 55-9 De-Ice, LabGene Denmark). The hydrodynamic size of the functionalized multiwall carbon nanotubes was measured by dynamic light scattering (DLS) using Malvern's Zetasizer Nano ZS recorded at $25{ }^{\circ} \mathrm{C}$.

\section{Pericardial matrix preparation}

Pericardial tissue was harvested from young adult sheep heart and immediately transferred to the clean room on the dry ice. The pericardial matrix from the sheep heart was harvested as per the ethical guidelines approved by the Institutional Animal Care and Use Committee of the Department of the Veterinary Surgery and Radiology, Faculty of Veterinary Medicine, University of Tehran. The experiments were performed conforming to the Helsinki ethical guidelines for the use of animals. The excess adipose tissue was carefully dissected and the remaining tissue was washed several times with deionized water. The pericardium was then cut into small pieces and the decellularization step was initiated. Briefly, samples were immersed in deionized water at $37{ }^{\circ} \mathrm{C}$ for 30 minutes and transferred to $0.05 \%$ Trypsin/0.02\% EDTA (Sigma T3924) at $37^{\circ} \mathrm{C}$ for 2 hours. Samples were subsequently washed with 1X PBS (Sigma P5368) for 15 minutes at room temperature and suspended in 3\% Triton X-100 (Sigma X100) at $4{ }^{\circ} \mathrm{C}$ for 24 hours. Thereafter, samples were washed three times with $1 \mathrm{X}$ PBS followed by a deionized water cycle for 15 minutes each and finally washed in deionized water for 30 minutes at room temperature. The decellularized pericardial matrix was lyophilized for $48 \mathrm{~h}$ and then cut and grounded in the fine granular pericardial matrix.

\section{Characterization of decellularized tissue}

Hematoxylin and eosin ( $\mathrm{H} \& \mathrm{E})$ staining assay, as previously described, ${ }^{\mathbf{1 6}}$ were performed on the decellularized tissues to evaluate any traces of the remaining cells in the decellularized tissue matrix. Fresh and decellularized tissues were fixed using $10 \%$ formalin $(24 \mathrm{~h})$ and were paraffin embedded. Samples were sectioned in $10 \mu \mathrm{m}$ thick slices and mounted on the glass slides. Hematoxylin and eosin staining was performed on both fresh and decellularized samples in order to assess the morphology of the decellularized tissue and also to identify the nuclear dots stained by hematoxylin in the fresh and decellularized tissue. Slides were imaged on $20 \times$ magnification using Nikon ECLIPSE Ti microscope made in Japan. Deoxyribonucleic acid (DNA) quantification was performed with 4',6-diamidino-2-phenylindole dihydrochloride (DAPI) staining. Fresh and decellularized tissues were fixed and permeabilized with $4 \%$ paraformaldehyde and $2.5 \%$ Triton X-100 in Dulbecco's phosphate buffered saline (DPBS) (Sigma D8537) for $15 \mathrm{~min}$; thereafter, $5 \mu \mathrm{g} \mathrm{mL} \mathrm{m}^{-1}$ DAPI (Sigma 32670 ) was added to the samples and incubated for 2 minutes at room temperature in the dark. Then, fluorescent intensity was recorded using the plate reader model Infinite 200 pro Tecan at the excitation/emission of 358/461 nm.

\section{Gel preparation}

The thermoresponsive gel was prepared as described previously. ${ }^{17,18}$ Briefly, the powdered ECM was digested in the $1 \mathrm{mg}$ $\mathrm{mL}^{-1}$ pepsin (Sigma P7012) solution in $0.1 \mathrm{M} \mathrm{HCl}$ for 72 hours. The $\mathrm{pH}$ of the digested matrix was adjusted to 7.4 using $1 \mathrm{M}$ $\mathrm{NaOH}$ and the concentration was set at $6 \mathrm{mg} \mathrm{mL}^{-1}$ by adding 
Dulbecco's phosphate buffered saline (DPBS) (Sigma D8537) at $\mathrm{pH}$ 7.4. The resulting viscous solution underwent gelation at $37{ }^{\circ} \mathrm{C}$ within 10 to 20 minutes. Pericardial matrix (PM) and the pericardial matrix containing $0.5 \mathrm{wt} \% \mathrm{CDH}-\mathrm{MWCNTs}$ (PMNT) were prepared by mixing the appropriate amounts of $\mathrm{CDH}$ MWCNT with the digested pericardial matrix and incubated at $37^{\circ} \mathrm{C}$ to induce gelation. The final concentration of the $\mathrm{CDH}-$ MWCNT was $0.03 \mathrm{mg} \mathrm{mL} \mathrm{m}^{-1}$.

\section{Morphological investigation}

Gel samples were prepared as described in the previous section and fixed with paraformaldehyde $4 \%$ in PBS for 1 hour. Thereafter, samples were rinsed with the 30, 50, 70 and $100 \%$ ethanol solution for 30 minutes each in order to promote gradual dehydration. PM and PMNT gels were immersed in the $100 \%$ ethanol and supercritically dried in order to preserve the microstructure of the nanofibrous gel. Samples were carefully cut into small pieces using a surgical blade. The surface morphology and the elemental study were performed using scanning electron microscopy dispersive X-ray spectroscopy (SEM-EDS, Leo 1550 SEM instrument Zeiss Germany).

\section{Rheometry}

Rheological measurements carried out using rheometer AR2000 TA instruments in duplicate to identify the physical properties of the produced gels. ${ }^{18} \mathrm{~A}$ frequency sweep test was carried out on PM and PMNT gels with the $8 \mathrm{~mm}$ diameter, the 1 mm gap space, and $5 \%$ strain from $0.5 \mathrm{rad} \mathrm{s}^{-1}$ to $100 \mathrm{rad} \mathrm{s}^{-1}$ and the storage $\left(G^{\prime}\right)$ and loss modulus $\left(G^{\prime \prime}\right)$ were measured.

\section{Hydrogel swelling}

Gels were incubated at room temperature in the PBS at the physiological condition at $\mathrm{pH} 7$ in duplicate. Then samples were placed in the vacuum dryer (Bioblock scientific) in order to dehydrate the swelled gels. The gels were weighed in wet $\left(W_{\mathrm{s}}\right)$ and dry $\left(W_{\mathrm{d}}\right)$ condition and then the swelling ratio was calculated using the following equation:

$$
Q=\frac{W_{\mathrm{s}}-W_{\mathrm{d}}}{W_{\mathrm{d}}} \times 100
$$

\section{Electrical conductivity measurements}

The electrical conductivity of the gels was measured by a custom-made four-point probe device with an electrode distance of $2 \mathrm{~mm}$ in triplicate. Briefly, gels were prepared at the thickness of $3 \mathrm{~mm}$ and incubated overnight at $37{ }^{\circ} \mathrm{C}$ to induce gelation. Gels were placed in the four-point probe device and the conductivity of the PM and PMNT samples were measured using the following equation.

$$
\sigma=\frac{\ln 2}{\pi} \times \frac{I}{V}
$$

where $\sigma$ is the conductivity of the hydrogel and $\pi / \ln 2$ is the geometrical factor considered as 4.53. $V$ and $I$ represents applied voltage and current respectively.

\section{Cell culture}

Pre-gel solutions of PM and PMNT were added to the 96 well plates and a $2 \mathrm{D}$ control group was prepared by coating the few wells with gelatin-fibronectin as the standard coating for the HL-1 cells (in triplicate). The HL-1 cells used in our study was gifted by Prof. Karl-Henrik Grinnemo from Karolinska Institute, Stockholm. Mice derived HL-1 cardiomyocytes were cultured in the supplemented Claycomb medium (Sigma 51800C) with 10\% FBS (Sigma F2442) 1\% penicillin/streptomycin (Sigma P4333) 1\% norepinephrine (Sigma A0937) and 1\% L-glutamine (Sigma 59202C) as previously described. ${ }^{19}$ The cells were subsequently trypsinized and seeded on the gelled solution for 3D culture and gelatin-fibronectin coated wells for $2 \mathrm{D}$ culture. The samples were incubated at $37^{\circ} \mathrm{C}$ for different days as indicated below.

\section{Cellular proliferation}

The proliferation of cells was measured by the Alamar ${ }^{\circledR}$ blue assay in triplicate as described elsewhere. ${ }^{20}$ Briefly, Alamar ${ }^{\circledR}$ blue dye (Fisher Scientific 10099022) was diluted in the Claycomb medium to $10 \%$ and added to the cells on the gel at different time points and cells were incubated for 2 hours at $37{ }^{\circ} \mathrm{C}$ and $5 \% \mathrm{CO}_{2}$. Subsequently, samples were retrieved and fluorescent intensity was read at 560/590 nm using plate reader model Infinite 200 pro-Tecan at gain 80 . Live and dead staining has been carried out for the cells inside the gels as previously described. ${ }^{21}$ A solution of the $4 \mu \mathrm{M}$ of the Ethidium homodimer1 (EthD-1) and $2 \mu \mathrm{M}$ of the calcein-AM was prepared in DPBS. At the day 1 and 11, samples were washed with pre-warmed DPBS and $250 \mu \mathrm{L}$ of the live and dead solution was added to the samples with the culture medium, incubated for 30 minutes at room temperature and fluorescently imaged using a Nikon ECLIPSE Ti microscope.

\section{Immunostaining}

Four well chamber slides (Fisher Scientific 154917) were used for the immunostaining of HL-1 cells. A $500 \mu \mathrm{L}$ gel solutions were dispensed onto the wells in the chamber slides and incubated at $37{ }^{\circ} \mathrm{C}$ to induce gelation forming a thick coat layer on the glass slide. HL-1 cells were cultured on top of the prepared gels in a density of 40000 cells per well. Immunostaining was done as described elsewhere. ${ }^{19}$ Briefly, after seven days, cells were washed with DPBS and fixed with $4 \%$ paraformaldehyde at pH 7.4 for $15 \mathrm{~min}$. After three rinses in DPBS, cells were permeabilized with $0.25 \%$ Triton X-100 in DPBS for $20 \mathrm{~min}$ for intracellular staining followed by three rinses in DPBS. Cells were blocked with the 10\% normal goat serum (Sigma G9023) for 1 hour to block unspecific binding of the antibodies at room temperature. Samples were rinsed with DPBS three times for 5 min each and incubated with the anti-mouse $\alpha$-actinin (Sigma A7811, 5c5, 1:500) in 1\% normal goat serum in DPBS containing 1\% Tween-20 (Fisher Scientific 11417160) (PBST) overnight at $4{ }^{\circ} \mathrm{C}$ as the first primary antibody. Subsequently, the first primary antibody solution was removed and the cells were rinsed three times in Tris-buffered saline $+1 \%$ Tween-20 (Fisher Scientific 10776834) (TBST) for $5 \mathrm{~min}$ each. Thereafter, cells 
were incubated with anti-mouse IgM (Sigma F9259 $\mu$-chain specific - FITC antibody produced in goat 1:200) in 1\% normal goat serum in PBST for $1 \mathrm{~h}$ at room temperature in the dark. Subsequently, the first secondary antibody solution was removed and cells were rinsed three times in DPBS for $5 \mathrm{~min}$ each in the dark. Second blocking step was done by incubating cells with the $10 \%$ normal goat serum for $30 \mathrm{~min}$ at room temperature in the dark and cells were incubated with the anticonnexin 43 antibody produced in rabbit (Sigma C6219 1:100) in $1 \%$ normal goat serum in PBST for $1 \mathrm{~h}$ at room temperature followed by three rinses with TBST for five minutes each. Cells were then incubated with Anti-Rabbit IgG (Sigma SAB3700858, Fc Specific-Texas Red ${ }^{\circledR}$ antibody produced in goat 1:500) in 1\% normal goat serum with PBST for $1 \mathrm{~h}$ at room temperature in the dark and rinsed three times with DPBS for 5 min each. In order to counterstain cellular nucleus, cells were incubated with $5 \mu \mathrm{g} \mathrm{mL}{ }^{-1}$ of DAPI for $1 \mathrm{~min}$ at room temperature in the dark, rinsed with DPBS and imaged using a Nikon ECLIPSE Ti microscope or Zeiss LSM 800 laser confocal microscope. Acquired images were analyzed using the Fiji image analysis software. The fluorescent intensity of each marker was quantified and the total mean intensity was calculated by dividing the sum of the integrated intensity by the sum of the surface area.

\section{Contractile activity of HL-1 cells}

Contractile activity of HL-1 cells was measured as described elsewhere. ${ }^{19}$ Briefly, 100000 cells were seeded on top of the gels in 12 well plates and after four days, they were washed with DPBS and incubated with $10 \mu \mathrm{M}$ Fluo-4 (Sigma T2145) in supplemented Claycomb medium for 30 min protected from the light. Thereafter, in order for the Fluo-4 to de-esterify, cells were rinsed in Tyrode's solution containing $5 \mathrm{mM}$ glucose (Sigma G7021), 5 mM HEPES (Sigma H4034), 10 mM norepinephrine (Sigma A0937) and $20 \mathrm{mM}$ ascorbic acid (Sigma A8960) at room temperature. Subsequently, cells incubated for another $20 \mathrm{~min}$ in Tyrode's solution at room temperature and imaged by Nikon ECLIPSE Ti microscope in a time-lapse mode at $195 \mathrm{~ms}$ intervals for 50 loops. Acquired images were analyzed by Fiji image analysis software. A $z$-plot graph was obtained from three independent regions of interest (ROI) and the fluorescent intensity $(I)$ was normalized by the minimum intensity $\left(I_{\min }\right)$ and the graph was plotted as $I / I_{\min }$ over time for each sample.

\section{Statistics}

Statistical analysis was performed by Microsoft excel software. All groups analyzed represent independent experiments. Data from each of the groups were compared using two-tailed student $T$-test. Values are reported as the mean \pm standard deviation. $P$-values less than 0.05 were considered as statistically significant.

\section{Results and discussion}

We have designed a thermoresponsive sheep pericardial matrix derived hydrogel as a scaffold for cardiac tissue engineering. To begin with, we first isolated the sheep pericardium from the freshly excised sheep heart and decellularized it following the reported procedure. ${ }^{18}$ The efficiency of the matrix decellularization was confirmed by $\mathrm{H} \& \mathrm{E}$ staining (Fig. $1 \mathrm{a}$ and $\mathrm{b}$ ) and nuclear DNA staining by DAPI (Fig. 1c). No cells were detected by $\mathrm{H} \& \mathrm{E}$ staining after decellularization (Fig. 1b) and the intensity of remnant genetic material as stained by DAPI was lower than $4 \%$ in the decellularized tissue as observed by others. ${ }^{22}$ The purified matrix was digested with pepsin in $0.1 \mathrm{M}$ HCl to obtain a viscous solution which has demonstrated thermoresponsive characteristics by rapid gelation when brought from $24^{\circ} \mathrm{C}$ to $37^{\circ} \mathrm{C}$ at physiological pH. To enhance the gel with the electrical conductivity, we doped it with $\mathrm{CDH}_{-}$ MWCNT. The incorporation of carbon nanotubes in composite materials has been successfully employed for various tissue engineering applications. ${ }^{23-26}$ One of the most challenging aspects of the application of MWCNT is the inherent hydrophobicity resulting in reduced dispersion and rapid aggregation in water. ${ }^{27}$ Different strategies have been devised to overcome this problem such as dispersion and ultra-sonication in various solvent systems such as trifluoroethanol ${ }^{28}$ and ethanol-water mixture ${ }^{29}$ or using functionalized CNTs as moist cakes, ${ }^{30}$ however, these approaches has met with partial success.

Inspired by our earlier reported use of $\mathrm{CDH}$ to design exceptionally stable hyaluronic acid hydrogels ${ }^{15}$ we have identified a straightforward and efficient strategy to obtain a highly dispersible MWCNT by functionalizing it with the CDH moiety (Fig. 2a). The commercially available $\mathrm{COOH}-\mathrm{MWCNT}$ displayed aggregation after 15 minutes of sonication in water when
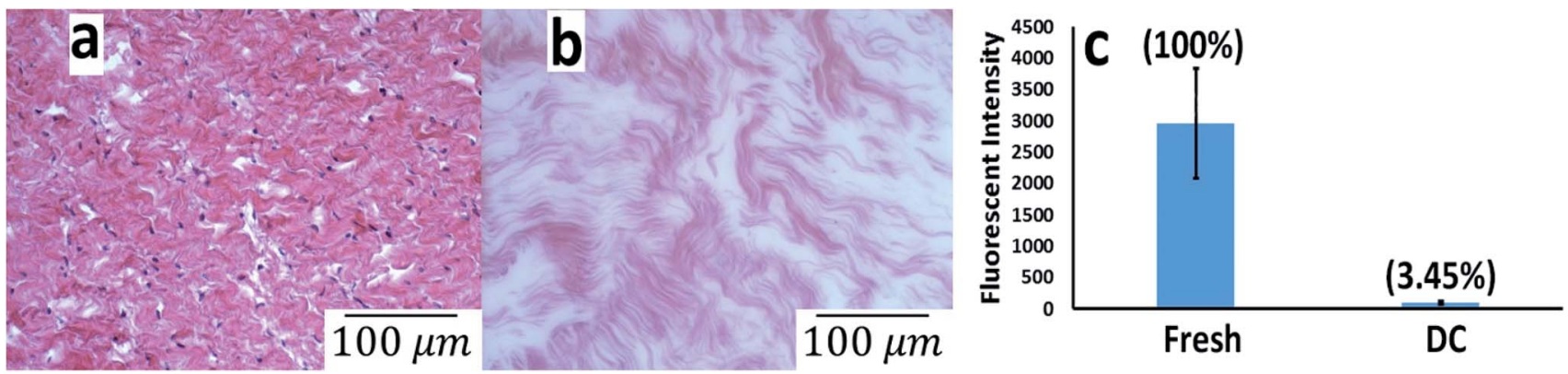

Fig. 1 Hematoxylin \& Eosin staining 200X microscopic images of the (a) fresh and (b) decellularized pericardial tissue with a scale bar of $100 \mu \mathrm{m}$ and (g) DNA quantification of the fresh and decellularized pericardial tissue by DAPI staining. 

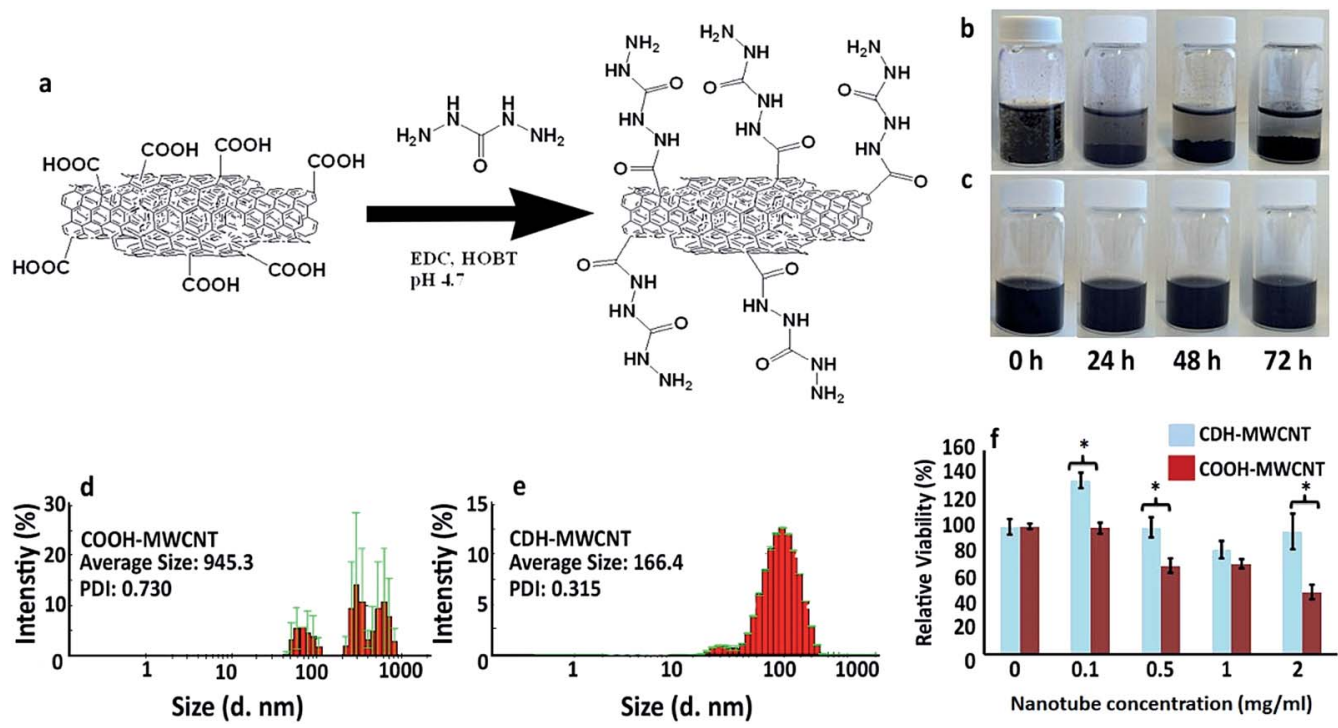

Fig. 2 (a) Schematic representation of the chemical modification of the nanotubes; stability of the dispersed (b) COOH-MWCNT and (c) CDHMWCNT from 0 to 72 hours; (d) dynamic light scattering spectrograph of $\mathrm{COOH}-\mathrm{MWCNT}$ and (e) $\mathrm{CDH}-\mathrm{MWCNT}$ and (f) viability results of treating cardiomyocytes with different concentrations of MWCNTs after $60 \mathrm{~h}$.

sonicated for $1 \mathrm{~h}$ (Fig. 2b) while CDH-MWCNTs were stable upon dispersion even after $72 \mathrm{~h}$ (Fig. 2c). Furthermore, $\mathrm{COOH}-$ MWCNT displayed a heterogeneous multimodal distribution (Fig. 2d) whereas CDH-MWCNT displayed a uniform distribution with an average size of $\approx 166 \mathrm{~nm}$ as observed by DLS analysis (Fig. 2e). To evaluate the functional characteristics of our composite hydrogel, we utilized HL-1 cells, a mouse cardiomyocyte cell line, which possesses a close resemblance to human primary cardiomyocytes. This cell line has been extensively used as a model to gain a better understanding of cardiac physiology at the cellular and molecular levels. ${ }^{31}$ Cytotoxicity of conductive polymers and matrix is another important parameter for engineering tissue engineering scaffolds. Cytotoxicity and immune activation potential of CNT depends on the surface properties and the size. ${ }^{32}$ Pristine CNT is hydrophobic and aggregates under aqueous conditions and trigger genotoxicity, immunogenicity and exhibit poor biocompatibility. ${ }^{32,33}$ However, surface functionalization of CNT improves the dispersibility of CNT under aqueous conditions and block inflammatory response after subcutaneous or intravenous administration. ${ }^{34}$ We evaluated the cytotoxicity of the carboxylate functionalized MWCNT and CDH-MWCNT to HL-1 cells. Interestingly, we found that CDH-MWCNT exhibited superior compatibility and cell viability as compared to the commercially available COOH-MWCNT (Fig. 2f). We, therefore, used this biocompatible and highly dispersible CDH-MWCNT for fabricating the composite pericardial matrix scaffold.

The PMNT hydrogel was prepared by physically mixing the CDH-MWCNT solution with the pre-gelled PM solution at room temperature and subsequent incubation at $37^{\circ} \mathrm{C}$. We utilized only $0.5 \mathrm{wt} \%$ of CDH-MWCNT for developing composite PMNT gels anticipating that such a low amount of dopant would preserve the biochemical cues of the native pericardium, enhance the mechanical properties of the gel and would not evoke any detrimental biological side effect. Obtaining homogenously dispersed $\mathrm{COOH}-\mathrm{MWCNT}$ in the hydrogels was not possible due to aggregation of COOH-MWCNTs. To investigate the micromorphology of the hydrogels, we adopted a supercritical $\mathrm{CO}_{2}$ mediated drying technique to minimize process induced structural changes. Scanning electron microscopy (SEM) images of the supercritically dried hydrogels showed a nanofibrous structure with a fiber diameter lower than $100 \mathrm{~nm}$ (Fig. 3a and b) preserving similar microstructural nanofibrous morphology between PM and PMNT. This microstructure reveals a structural resemblance to that of the native myocardium containing electroconductive hyperbranched and crosslinked Purkinje fibers. ${ }^{35,36}$ Energy-dispersive X-ray spectroscopy (EDS) analysis of the supercritically dried PMNT gels revealed a nitrogen signal confirming the presence of hydrazide functional groups, which was absent in PM gels (Fig. 3c and d). Furthermore, the higher carbon signal in PMNT gels confirmed the presence of the nanotubes in the construct. However, traces of some heavy metals in the PMNT related to the impurities during the MWCNT synthesis were inevitable. We further characterized the PM and PMNT hydrogels by a rheological investigation. Doping of PM gel with $0.5 \mathrm{wt} \%$ CDH-MWCNT (i.e., $0.03 \mathrm{mg} \mathrm{mL}^{-1}$ ) increased the storage modulus from 97.22 Pa to $229.25 \mathrm{~Pa}$ (Fig. 3e). This stiffer material with a significant increase in storage modulus and slightly increased loss modulus can serve as a functional scaffold in the continuously beating cardiac tissue. PMNT also exhibited slightly lower swelling than the PM gels (Fig. 3f). Interestingly, the dynamic viscosity of PM and PMNT gel were not different, suggesting that incorporation of CDH-MWCNT in PM gel did not alter the injectability of these gels, though yielded a stiffer hydrogel (Fig. 3g). The electrical conductivity of PM and PMNT gels was evaluated using a four-point probe as described in the previous report. ${ }^{37}$ As anticipated, the addition of CDH-MWCNT to the gel 

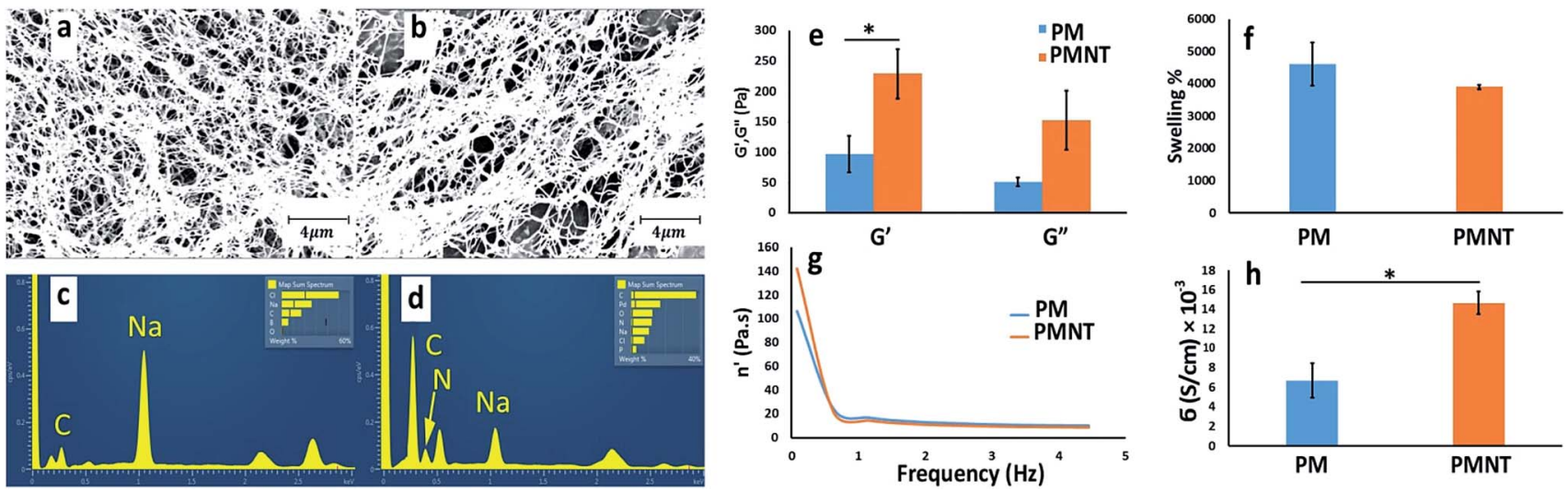

Fig. 3 SEM images of the (a) PM and (b) PMNT gels with scale bar $4 \mu \mathrm{m}$. Energy-dispersive X-ray spectroscopy analysis of the (c) PM and (d) PMNT gels. The metallic elements presented in the spectrum are related to the impurities of the MWNTs. Rheological (e) storage and loss modulus of the PM and PMNT gels that is an indication of the solid-like behavior of these gels and (f) the swelling ratio calculated as the ratio of the difference in dry and wet weight of the gel by the weight of the dry gel. (g) Dynamic viscosity of the gels which is decreased by increasing the frequency and (h) the electrical conductivity of the gels measured by four-point probe.

gave a significant increase in the electrical conductivity from $0.007 \mathrm{~S} \mathrm{~cm}^{-1}$ for PM gels to $0.015 \mathrm{~S} \mathrm{~cm}^{-1}$, this value is closer to the cardiac tissue's conductivity at $0.1 \mathrm{~S} \mathrm{~cm}^{-1}$ that was demonstrated to induce synchronous cardiomyocyte beating (Fig. 3h).

We next investigated the functional aspects of PM and PMNT gels by seeding HL-1 cardiomyocytes cells. Transplantation of cardiomyocytes after myocardial infarction has been reported to improve cardiac function as it prevents scar expansion and assists in increasing contractility. ${ }^{38}$ However, this strategy depends on the survival and the integration of the exogenous cells to the cardiac tissue with synchronized beating. Such integration will promote reinforcement of the injured tissue and prevent arrhythmia. To determine the biocompatibility of our scaffold, we seeded HL-1 cells on PM and PMNT gels; then, the proliferation rate and the expression of the cardiac specific markers were evaluated. Cells cultured on gelatin-fibronectin coated plates (2D-control) were used as a control as the standard method for culturing HL-1 cells. ${ }^{31,39}$ The Alamar® blue studies revealed that the cells grown on PM gels remained stable and did not proliferate which could be a result of the lower stiffness of the PM gels which made them soft enough to hinder cellular proliferation, while the cells on the PMNT gels sensed the presence of nanotubes and triggered proliferation on the stiffer PMNT gels (Fig. 4a). This is presumably due to the fact that cells prefer stiffer surfaces to adhere and proliferate and therefore the presence of CDH-MWCNT in the cellular microenvironment triggered such a cellular response. The proliferation of cells was also corroborated by the live and dead staining of HL-1 cardiomyocytes in an 11 day culture condition, which showed a high cellular viability, with only a few dead cells. However, the gelatinfibronectin coated 2D culture exhibited a high number of dead cells (Fig. S1 in ESI†). This can be also a justification on how 3D cell culture can help cells survive for longer periods compared with the monolayer and 2D cultures.

We further conducted immunofluorescence staining on cells cultured for seven days on PM and PMNT gels to determine the level of cardiac functional markers sarcomeric $\alpha$-actinin and connexin-43 (Cx43). We found that cells which grown on PM and PMNT gels exhibited almost equal levels of the sarcomeric $\alpha$-actinin, that was higher than the 2D control group suggesting a similar cytoskeletal arrangement in the cardiomyocytes for these gels (Fig. 4b and S2 in ESI†). Interestingly, the Cx43 levels were significantly elevated in the PMNT group when compared with PM gels and the 2D control group (Fig. $4 \mathrm{~b}$ and d). The high expression of the cardiac gap junction protein $\mathrm{Cx} 43$ indicates favorable cell-cell communication, growth, and differentiation. The Cx43 has a significant role in cardiac function, as it is known to regulate the cell-cell interaction, promote electrical coupling, and regulate the contractile behavior. ${ }^{40,41}$ The higher Cx43 expression clearly indicates a superior electrical coupling between the adjacent cells when cultured on a conductive gel. However, this could not be attributed solely to the presence of MWCNT, as cardiomyocytes are cultured on CNT functionalized gelatin hydrogel (containing as high as $5 \mathrm{mg} \mathrm{mL}^{-1}$ of CNT), did not result in higher expression of $\mathrm{Cx} 43 .{ }^{35}$ Although the main component of PM is collagen, cardiomyocytes cultured on collagen sponge and Matrigel failed to express elevated levels of Cx43, without electrical stimulation. ${ }^{42}$ Thus, the cardiac specific ECM cues present in PM together with CDH-MWCNT synergistically stimulate the higher expression of $\mathrm{Cx} 43$ resulting in superior cell alignment, the cell-cell communication and contractibility, without any external electrical stimulation.

Other important aspects of cardiomyocyte transplantation are clustering and synchronous beating of the cells. The synchronous beating of the cardiomyocytes was reported after an electrical stimulation of aligned electroconductive polyaniline in poly(lactic-co-glycolic acid). ${ }^{43}$ Interestingly, HL-1 cells cultured on PMNT gels formed a significantly higher number of clusters than PM gels while cells cultured on gelatin-fibronectin coated 2D cell culture plate did not form any clusters (Fig. 4d). Thereafter, we measured the contractility and the frequency of the beating of the HL-1 cells using calcium sensitive Fluo-4 reagent (Fig. 4c). We observed that the cells cultured on the 

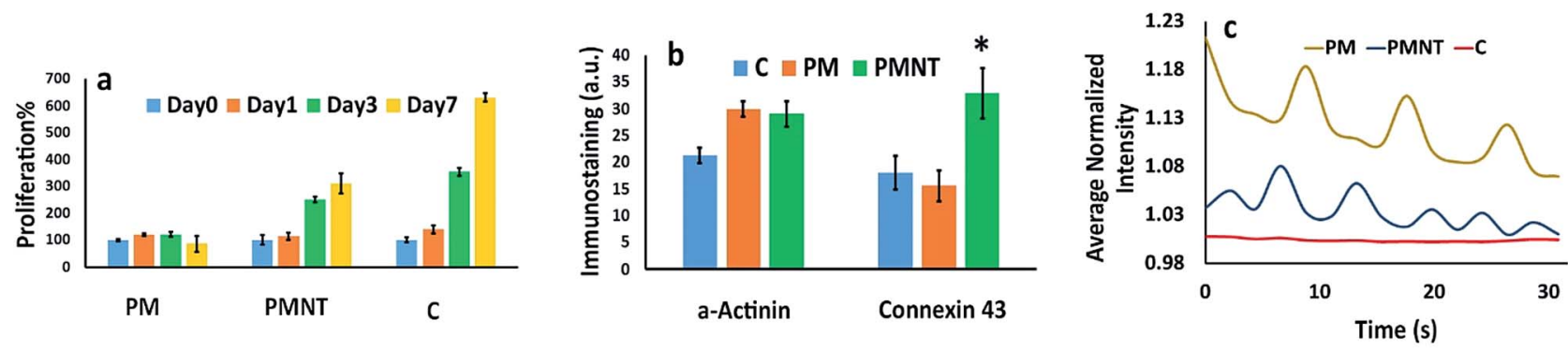

d Control

PM

PMNT

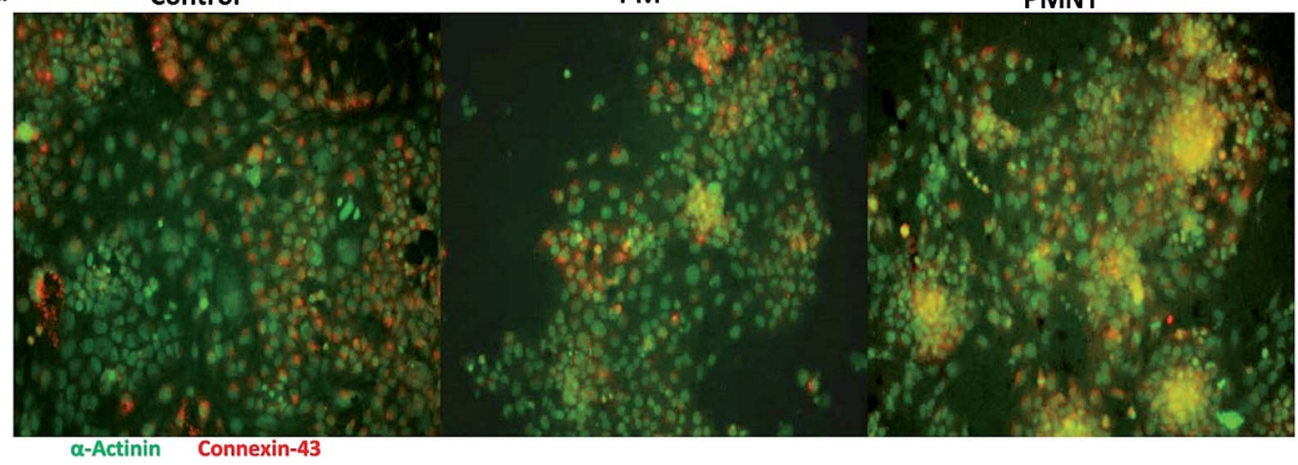

Fig. 4 (a) Proliferation results by Alamar Blue assay from day 0 to day 7 and (b) quantified expression of the Cx43 and alpha-actinin at the day 7 , (c) beating frequency of cardiomyocytes on PM and PMNT gels and control group. The decrease in the intensity with time of the individual group is due to the fluorescent bleaching, (d) immunostaining images of the expression of the Cx43 and alpha-actinin by cardiomyocytes cultured on the gels.

PM and PMNT gels were beating synchronously and their beating was directional (Videos V2 and V3 in ESI $\dagger$ ). On the contrary, cells in the 2D gelatin-fibronectin coated cell culture plate (control group) did not show any beating activity (Video V1 in ESI $\dagger$ ). Intriguingly, cells cultured on the PMNT gels possessed a twofold higher frequency as compared to the PM groups. Taken together, these results indicate that PMNT scaffold is superior to conventional scaffolds, as they possess the niche for cardiac cells with improved conductivity.

\section{Conclusions}

We have designed a unique sheep PM derived scaffold doped with MWCNT-CDH that form an excellent platform for cardiac applications as it possesses many of the necessary biological and physical cues for cell proliferation and function. Incorporation of highly dispersive MWCNT into this scaffold enhanced its mechanical properties and electrical conductivity that on the other hand increased the cellular viability, the expression of a cardiac marker such as Cx34 and improved the beating of the cardiomyocytes favourably by facilitating the electrical coupling of the adjacent cells. The expression of cardiac specific sarcomeric $\alpha$-actinin was higher in PM and PMNT gels compared to the 2D control. The PMNT hydrogel design presented in this study overcomes significant challenges of cardiac scaffold design such as electrical communications between cellular gap junctions, survival and proliferation of the cells with the significant biocompatibility of the scaffold. Moreover, our study demonstrates that electrical stimulation of cardiomyocytes may not be necessary for generating electrical communication at gap junctions or to trigger synchronized beating of the cells. We believe the novel PMNT scaffold presented in this study has the potential for clinical translation as it addresses some of the fundamental aspects such as cell-cell electrical conductivity and cell-matrix interactions that are the key for cardiac tissue regeneration. The electroactive composite hydrogel developed in this study could be useful for culturing electroactive cells and tissue regeneration of muscles and neurons that require electrical conductivity.

\section{Author contributions}

The project was conceived and designed by OPO and KR, the experiments and data acquisition was undertaken by $\mathrm{KR}$, the manuscript was drafted by OPO, all authors have critically evaluated the data and gave the intellectual contribution. All authors have contributed to writing this manuscript.

\section{Acknowledgements}

We acknowledge the support and assistance from Dr Zahra Mohammadi and Dr Abdorreza S. M. Mesgar from the University of Tehran for providing help in harvesting animal tissue.

\section{Notes and references}

1 D. Mozaffarian, E. J. Benjamin, A. S. Go, D. K. Arnett, M. J. Blaha, M. Cushman, S. de Ferranti, J. P. Despres, 
H. J. Fullerton, V. J. Howard, M. D. Huffman, S. E. Judd, B. M. Kissela, D. T. Lackland, J. H. Lichtman, L. D. Lisabeth, S. M. Liu, R. H. Mackey, D. B. Matchar, D. K. McGuire, E. R. Mohler, C. S. Moy, P. Muntner, M. E. Mussolino, K. Nasir, R. W. Neumar, G. Nichol, L. Palaniappan, D. K. Pandey, M. J. Reeves, C. J. Rodriguez, P. D. Sorlie, J. Stein, A. Towfighi, T. N. Turan, S. S. Virani, J. Z. Willey, D. Woo, R. W. Yeh, M. B. Turner, A. H. A. S. Comm and S. S. Subcomm, Circulation, 2015, 131, E29-E322.

2 A. Le Huu, S. Prakash and D. Shum-Tim, Regener. Med., 2012, 7, 571-582.

3 K. A. Robinson, J. Li, M. Mathison, A. Redkar, J. Cui, N. A. Chronos, R. G. Matheny and S. F. Badylak, Circulation, 2005, 112, I135-I143.

4 S. B. Seif-Naraghi, M. A. Salvatore, P. J. Schup-Magoffin, D. P. Hu and K. L. Christman, Tissue Eng., Part A, 2010, 16, 2017-2027.

5 E. C. Martinez and T. Kofidis, Expert Rev. Cardiovasc. Ther., 2009, 7, 921-928.

6 J. M. Singelyn, J. A. DeQuach, S. B. Seif-Naraghi, R. B. Littlefield, P. J. Schup-Magoffin and K. L. Christman, Biomaterials, 2009, 30, 5409-5416.

7 R. M. Wang and K. L. Christman, Adv. Drug Delivery Rev., 2016, 96, 77-82.

8 M. Radisic, H. Park, H. Shing, T. Consi, F. J. Schoen, R. Langer, L. E. Freed and G. Vunjak-Novakovic, Proc. Natl. Acad. Sci. U. S. A., 2004, 101, 18129-18134.

9 R. Balint, N. J. Cassidy and S. H. Cartmell, Acta Biomater., 2014, 10, 2341-2353.

10 D. Kai, M. P. Prabhakaran, G. Jin and S. Ramakrishna, J. Biomed. Mater. Res., Part A, 2011, 99, 376-385.

11 P. M. George, A. W. Lyckman, D. A. LaVan, A. Hegde, Y. Leung, R. Avasare, C. Testa, P. M. Alexander, R. Langer and M. Sur, Biomaterials, 2005, 26, 3511-3519.

12 E. I. Yslas, L. E. Ibarra, D. O. Peralta, C. A. Barbero, V. A. Rivarola and M. L. Bertuzzi, Chemosphere, 2012, 87, 1374-1380.

13 S. R. Shin, S. M. Jung, M. Zalabany, K. Kim, P. Zorlutuna, S. B. Kim, M. Nikkhah, M. Khabiry, M. Azize, J. Kong, K.-t. Wan, T. Palacios, M. R. Dokmeci, H. Bae, X. Tang and A. Khademhosseini, ACS Nano, 2013, 7, 2369-2380.

14 V. Martinelli, G. Cellot, F. M. Toma, C. S. Long, J. H. Caldwell, L. Zentilin, M. Giacca, A. Turco, M. Prato, L. Ballerini and L. Mestroni, Nano Lett., 2012, 12, 18311838.

15 O. P. Oommen, S. J. Wang, M. Kisiel, M. Sloff, J. Hilborn and O. P. Varghese, Adv. Funct. Mater., 2013, 23, 12731280.

16 J. L. Ungerleider, T. D. Johnson, N. Rao and K. L. Christman, Methods, 2015, 84, 53-59.

17 S. B. Seif-Naraghi, D. Horn, P. J. Schup-Magoffin and K. L. Christman, Acta Biomater., 2012, 8, 3695-3703.

18 S. B. Seif-Naraghi, M. A. Salvatore, P. J. Schup-Magoffin, D. P. Hu and K. L. Christman, Tissue Eng., Part A, 2010, 16, 2017-2027.
19 L. R. Geuss, A. C. B. Allen, D. Ramamoorthy and L. J. Suggs, Biotechnol. Bioeng., 2015, 112, 1446-1456.

20 F. Bonnier, M. E. Keating, T. P. Wrobel, K. Majzner, M. Baranska, A. Garcia-Munoz, A. Blanco and H. J. Byrne, Toxicol. in Vitro, 2015, 29, 124-131.

21 B. L. Apostol, A. Kazantsev, S. Raffioni, K. Illes, J. Pallos, L. Bodai, N. Slepko, J. E. Bear, F. B. Gertler, S. Hersch, D. E. Housman, J. L. Marsh and L. M. Thompson, Proc. Natl. Acad. Sci. U. S. A., 2003, 100, 5950-5955.

22 H. C. Ott, T. S. Matthiesen, S.-K. Goh, L. D. Black, S. M. Kren, T. I. Netoff and D. A. Taylor, Nat. Med., 2008, 14, 213-221.

23 S. Ostrovidov, X. T. Shi, L. Zhang, X. B. Liang, S. B. Kim, T. Fujie, M. Ramalingam, M. W. Chen, K. Nakajima, F. AlHazmi, H. Bae, A. Memic and A. Khademhosseini, Biomaterials, 2014, 35, 6268-6277.

24 R. A. MacDonald, B. F. Laurenzi, G. Viswanathan, P. M. Ajayan and J. P. Stegemann, J. Biomed. Mater. Res., Part A, 2005, 74, 489-496.

25 W. M. Chiu, Y. A. Chang, H. Y. Kuo, M. H. Lin and H. C. Wen, J. Appl. Polym. Sci., 2008, 108, 3024-3030.

26 S. D. McCullen, K. L. Stano, D. R. Stevens, W. A. Roberts, N. A. Monteiro-Riviere, L. I. Clarke and R. E. Gorga, J. Appl. Polym. Sci., 2007, 105, 1668-1678.

27 J. Hilding, E. A. Grulke, Z. G. Zhang and F. Lockwood, J. Dispersion Sci. Technol., 2003, 24, 1-41.

28 J. Zhou, J. Chen, H. Y. Sun, X. Z. Qiu, Y. C. Mou, Z. Q. Liu, Y. W. Zhao, X. Li, Y. Han, C. M. Duan, R. Y. Tang, C. L. Wang, W. Zhong, J. Liu, Y. Luo, M. Xing and C. Y. Wang, Sci. Rep., 2014, 4, 3733.

29 J. J. Shi, R. R. Ma, L. Wang, J. Zhang, R. Y. Liu, L. L. Li, Y. Liu, L. Hou, X. Y. Yu, J. Gao and Z. Z. Zhang, Int. J. Nanomed., 2013, 8, 2361-2373.

30 C. Zamora-Ledezma, L. Buisson, S. E. Moulton, G. Wallace, C. Zakri, C. Blanc, E. Anglaret and P. Poulin, Langmuir, 2013, 29, 10247-10253.

31 S. M. White, P. E. Constantin and W. C. Claycomb, Am. J. Physiol.: Heart Circ. Physiol., 2004, 286, H823H829.

32 D. L. Kirkpatrick, M. Weiss, A. Naumov, G. Bartholomeusz,

R. B. Weisman and O. Gliko, Materials, 2012, 5, 278.

33 S. Toyokuni, Adv. Drug Delivery Rev., 2013, 65, 2098-2110.

34 Z. Liu, K. Chen, C. Davis, S. Sherlock, Q. Cao, X. Chen and

H. Dai, Cancer Res., 2008, 68, 6652.

35 S. R. Shin, S. M. Jung, M. Zalabany, K. Kim, P. Zorlutuna, S. B. Kim, M. Nikkhah, M. Khabiry, M. Azize, J. Kong, K. T. Wan, T. Palacios, M. R. Dokmeci, H. Bae, X. W. Tang and A. Khademhosseini, ACS Nano, 2013, 7, 2369-2380.

36 A. J. Atkinson, S. J. R. J. Logantha, G. Hao, J. Yanni, O. Fedorenko, A. Sinha, S. H. Gilbert, A. P. Benson, D. L. Buckley, R. H. Anderson, M. R. Boyett and H. Dobrzynski, J. Am. Heart Assoc., 2013, 2, e000246.

37 S. Naficy, J. M. Razal, G. M. Spinks, G. G. Wallace and P. G. Whitten, Chem. Mater., 2012, 24, 3425-3433.

38 R. K. Li, D. A. G. Mickle, R. D. Weisel, J. Zhang and M. K. Mohabeer, Circ. Res., 1996, 78, 283-288. 
39 W. C. Claycomb, N. A. Lanson, B. S. Stallworth, D. B. Egeland, J. B. Delcarpio, A. Bahinski and N. J. Izzo, Proc. Natl. Acad. Sci. U. S. A., 1998, 95, 2979-2984.

40 M. Oyamada, H. Kimura, Y. Oyamada, A. Miyamoto, H. Ohshika and M. Mori, Exp. Cell Res., 1994, 212, 351-358.

41 M. Ando, R. G. Katare, Y. Kakinuma, D. M. Zhang, F. Yamasaki, K. Muramoto and T. Sato, Circulation, 2005, 112, 164-170.
42 M. Radisic, H. Park, H. Shing, T. Consi, F. J. Schoen, R. Langer, L. E. Freed and G. Vunjak-Novakovic, Proc. Natl. Acad. Sci. U. S. A., 2004, 101, 18129-18134.

43 C. W. Hsiao, M. Y. Bai, Y. Chang, M. F. Chung, T. Y. Lee, C. T. Wu, B. Maiti, Z. X. Liao, R. K. Li and H. W. Sung, Biomaterials, 2013, 34, 1063-1072. 